\title{
(Des)política para corpos-política na arte, na cultura e na educação ${ }^{1}$
}

\author{
OLIVEIRA, Marcos Antônio Bessa ${ }^{2}$
}

\section{RESUMO}

Arte, Educação, Política compõem uma tríade compreendida historicamente no Ocidente como interdependentes. Entretanto, arte, educação e políticas ocidentais não estão compreendidas para corpos aquém dos padrões de raça, gênero e classe edificados pelo pensamento que arquitetou o projeto moderno europeu levado à expansão em todo mundo no século XVI. Igualmente, histórico e contemporaneamente, políticas têm definido, no caso do Brasil em níveis federal, estaduais e municipais, atuações e ações de corpos e sobre os corpos na arte, na educação e na própria política. Considerando a histórica indissociação entre a tríade arte, educação e política, mas também a atual e fascista dissociação das políticas em relação aos corpos que atuam nas artes e na educação em contexto brasileiro contemporâneo, este artigo discuti, por uma perspectiva descolonial de abordagem bi(os)bliográfica, a falta de arte em política, educação em política e corpos em política que consideram as diferenças culturais e coloniais porque não contemplam o padrão de arte, educação, corpo e política modernos.

Arte. Educação. Política.

\section{(Dis) politics for political bodies in art, culture and education}

\begin{abstract}
Art, Education, Politics make up a triad historically understood in the West as interdependent. However, Western art, education and politics are not understood for bodies below the standards of race, gender and class built by thought that architected the modern European project led to expansion around the world in the sixteenth century. Similarly, historically and contemporatically, policies have defined, in the case of Brazil at federal, state and municipal levels, actions and actions of bodies and on bodies in art, education and politics itself.
\end{abstract}

\footnotetext{
1 Uma primeira versão deste texto foi apresentada como comunicação oral no XIV Ciclo de Investigações PPGAV UDESC 2019 da UEDESC Florianópolis/SC. Texto vinculado aos Projetos de Pesquisas cadastrados na PROPP/SUPRIDO e PROPP/SUPRIDO cujo título é "Suprido".

2 Doutor em Artes Visuais pelo IA-Unicamp. Mestre em Estudos de Linguagens. Professor do Curso de Artes Cênicas (Graduação), na Cadeira de Artes Visuais, e do Programa de Mestrado Profissional em Educação - PROFEDUC - da Universidade Estadual de Mato Grosso do Sul - UEMS. E-mail: marcosbessa2001@gmail.com. Lattes:

http://lattes.cnpq.br/7724599673552418. ORCID: https://orcid.org/0000-0002-4783-7903.
}

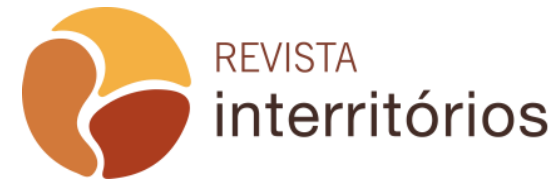

Interritórios | Revista de Educação Universidade Federal de Pernambuco, Caruaru, BRASIL | V.6 N.10 [2020] 
Considering the historical indissociation between the triad art, education and politics, but also the current and fascist dissociation of policies in relation to the bodies that work in the arts and education in a contemporary Brazilian context, this article discussed, for a decolonial perspective of bi(os)bliographical approach, lack of art in politics, education in politics and bodies in politics that consider cultural and colonial differences because they do not contemplate the standard of modern art, education, body and politics.

\section{Art. Education. Politics.}

\section{(Des) política para cuerpos-políticos en arte, cultura y educación}

\section{RESUMEN}

Arte, educación, política producen un trío históricamente entendido en el Occidente como interdependientes. Pero, el arte, la educación y las políticas occidentales no están incluidas para cuerpos con padrones inferiores a las normas de raza, género y clase construidas por el pensamiento que he producido el proyecto moderno europeo expandido en todo el mundo desde el siglo XVI. Asimismo, se han definido políticas históricas y contemporáneas, en el caso de Brasil, a nivel federal, estatal y municipal, actividades y acciones de cuerpos y sobre los cuerpos en el arte, en la educación y en la política. Considerando la indisociación histórica entre el trío arte, educación y política, pero también la actual y fascista desagregación de las políticas con relación a los cuerpos que actúan en las artes en la educación en el contexto brasileño contemporáneo, este artículo discutió, bajo un enfoque descolonial de abordaje bi(os)bliográfica, la ausencia de arte en política, educación en política y cuerpos en política que consideran las diferencias culturales y coloniales, porque no contemplan el estándar del arte, educación, cuerpo y política modernos.

Arte. Educación. Política.

\section{(Des) politica per gli organi politici nell'arte, nella cultura e nell'educazione}

\section{SINTESE}

Arte, educazione, politica producono un trio storicamente inteso in Occidente come interdipendente. Ma l'arte occidentale, l'istruzione e la politica non sono incluse per gli organismi con standard inferiori agli standard di razza, genere e classe costruiti dal pensiero che ho prodotto il moderno progetto europeo ampliato in tutto il mondo dal XVI secolo. Allo stesso modo, le politiche storiche e contemporanee sono state definite, nel caso del Brasile, a livello federale, statale e municipale, attività e azioni di corpi e di corpi nell'arte, nell'istruzione e nella politica. Considerando la dissociazione storica tra arte, istruzione e trio politico, ma anche l'attuale e fascista disaggregazione delle politiche in 
relazione agli organismi che agiscono nelle arti nell'educazione nel contesto brasiliano contemporaneo, questo articolo discute, sotto un approccio decoloniale approccio bi-os, assenza di arte in politica, educazione in politica e corpi politici che considerano le differenze culturali e coloniali, perché non contemplano lo standard dell'arte moderna, dell'educazione, del corpo e della politica.

Arte. Istruzione. Politica.

\section{Introdução - política (merdácea) brasileira}

Tales ideas han estado, además, asociadas a prácticas políticas indeseables, detrás del sueño de racionalización total de la sociedad. (QUIJANO, 1992, p. 19).

A epígrafe que antecede às discussões deste artigo consegue ilustrar a noção básica de que a tríade Arte, Educação, Política é compreendida atualmente como uma forma de padronização da cultura brasileira. Pois, "tais ideias também foram associadas a práticas políticas indesejáveis, por trás do sonho de total racionalização da sociedade" (QUIJANO, 1992, p. 19) (tradução livre minha), sob um rótulo de conservadorismo, que leva a construção de interdependência histórica dessa tríade ser atualmente ainda mais ressaltada por poderes políticos, para manter o pensamento que reafirma o projeto moderno europeu do século XVI em pleno século XXI, a fim de continuar a desclassificar/desqualificar corpos que se construíram sem obedecer aos padrões de raça, gênero e classe lá erigidos.

Do mesmo modo, as associações entre política partidária, histórica e contemporânea, com as políticas de arte e de educação têm definido, no caso do Brasil, toadas pelos recentes discursos de extrema-direita de nível federal, também nos âmbitos estaduais e municipais, os espaços (im)permissíveis de atuações e ações de corpos e sobre os corpos na arte, na educação e na própria política que deveriam atender a todos e todas. Assim, a histórica indissociação que atribuiu arte, educação e política às mãos de políticas públicas, igualmente a atuação fascista que contribui para a dissociação das políticas dos corpos das diferenças que atuam nas artes e na educação na contemporaneidade devem ser pensadas por uma perspectiva de investigação que toma o próprio corpo - bi(os)bliográfica ${ }^{3}$ - para debater a ausência de arte em política, educação em política e corpos em política das diferenças culturais e coloniais hoje no Brasil.

\footnotetext{
${ }^{3}$ Aqui estou pensando, antes de tudo, em uma relação entre o corpo do pesquisador que vive as situações/ações e as bibliografias que compõem seu repertório de leitura investigativa.
} 
As políticas nunca alcançaram as necessidades da arte, da educação e nem mesmo da própria política. Se fosse verdade que as atuais políticas resolvessem os problemas das necessidades da arte, da educação ou mesmo da política, talvez não tivéssemos mais essa política brasileira atual como necessárias. ${ }^{4}$ Logo, essas mesmas políticas não contemplaram as artes, as culturas, os conhecimentos dos diferentes e menos ainda das diferenças culturais e, pior ainda, das diferenças coloniais as quais quero contemplar nesta discussão. Deste modo, parece que a arte, a educação e a política nunca concordaram. Parece ainda que as políticas que deveriam contemplar as artes, a educação e se efetivarem como políticas públicas que assistem às necessidades dos que precisam nunca passaram de seleção de bem poucos dentre aos semelhantes seus (Eu) em contraposição aos muitos diferentes outros.

Digo isso primeiro porque as artes e a educação não obedecem às políticas, ou ao menos não o deveriam obedecer para existirem; segundo porque as políticas não estão para a arte e a educação como políticas para a formação social, crítica, econômica, cultural e política de indivíduos políticos e polidos, mas para fins político-partidários de dominação do que é construído como o outro; em terceiro lugar, o que faz a minha razão mais evidente de desconfiar da existência de políticas públicas efetivas, é que a arte, a educação e mesmo as políticas dessas não combinam entre si porque as políticas de arte e de educação no Brasil não estão fundamentadas em corpopolítica (MIGNOLO, 2008); pois são, na verdade, (des)políticas de arte, educação e do próprio conceito de política brasileiros.

A política no Ocidente, bem como a ética, a democracia e até a estética são baseadas na lógica grega de mundo ético, democrático e político. Entretanto, não é o caso da estética. Mas sobre essa espero poder abordar mais à frente ainda neste trabalho. Por ora, interessa-me dizer que se naquele momento os pensadores (políticos) tinham uma ideia de direito e de democracia que contemplavam cada vez mais e melhor os gregos que já tinham acesso em direitos e democracias, especialmente aos homens, na contemporaneidade continuamos, com nossas políticas, ética e direitos, insistindo naquela mesma lógica de continuar contemplando quem menos precisa de políticas de direitos.

Desta lógica em que as políticas não têm corpo, vamos dizer assim - a corpo-política que as políticas de arte e de educação, por exemplo, mas também as políticas públicas brasileiras de saúde, segurança, de direito e a

\footnotetext{
${ }^{4}$ Em um primeiro momento não estou pensando exclusivamente nas atuais políticas bolsominians, mas nas políticas de arte e de educação, igualmente de cultura, de segurança, políticas de saúde pública que sempre foram pensadas no Brasil em prol do desvio de dinheiro público que muito raramente foram políticas públicas que efetivamente atenderam às necessidades da população carente brasileira.
}

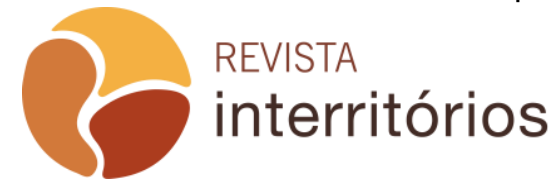

Interritórios | Revista de Educação Universidade Federal de Pernambuco, Caruaru, BRASIL | V.6 N.10 [2020] 
política de democracia, entre muitas outras diferenças coloniais que as políticas em evidência deveriam alcançar/contemplarem para estarem nominadas como políticas públicas de assistências -, a única forma de nos enxergarmos neste momento de crise da própria política (que se ancorou em um discurso fascista erigido sob a insígnia de uma "nova direita" extremista) é nos reconhecermos indivíduos descoloniais. É nos fazermos corpos em políticas! Evidentemente não estou argumentando sobre políticas de arte e de educação, como apoio a essas ou à falta desse apoio à arte e a educação como estão. Do mesmo modo não quero tratar da mesma forma que sempre fora dantes tratada às relações entre arte versus política, política versus educação e até política versus políticas.

Falar aqui da relação da corpo-política entre corpo/lócus de enunciação é pensar todas essas questões a partir da corpo-política como forma de evidenciar a importância de que as políticas públicas necessariamente não podem estar voltadas para gentes sem corpos e sem lugar específicos de fala. Quer dizer, as políticas públicas precisam levar em consideração as especificidades de corpos e de lugares para serem efetivas às necessidades dos diferentes corpos situados em seus lugares. Logo, estou propondo pensar em políticas públicas que não tratem o "um" como uma homogeneidade de "outro" construída também pela mesma lógica que sustenta nossas políticas: partidarismos. Assim, é preciso situar as políticas públicas brasileiras como assistenciais a partir do corpo situado em lugares das especificidades biogeográficas. ${ }^{5}$

Mesmo que o debate ainda tenha que passar por essas questões de "relações políticas" lembradas: fraternidades, familiaridades, hospitalidades, amizades (DERRIDA, 2003; ORTEGA, 2000), entre outras questões de imposições entre apolíticas que determinam limites de existência. Mas, ao contrário, vou preferir discutir neste trabalho as repressões políticas que estão levando à crise atual, na arte e na educação e na própria política, por causa de políticas partidárias ideológicas de extrema-direita que não se veem como políticas de restrição/seleção. ${ }^{6}$ Logo, as discussões evidenciarão que a corpopolítica é a "salvação" porque esta consciência promove a liberdade do corpo

\footnotetext{
${ }^{5}$ Nesta relação do "um" construído como uma homogeneidade de "outro", construção do "Eu" que se considera superior aos outros, tem bases em classificações sociais que definem acessos às políticas, direitos e democracias em sociedades que determinam acessos a partir de políticas de perspectivas ocidentais já citadas que se referendam na lógica grega.

${ }^{6}$ Agora sim estou falando das "políticas" atuais que estão sendo efetivadas pelos ministérios da Educação, da Economia e o Ministério da Justiça e Segurança Pública, por exemplo, que estão tratando as diferenças como igualdades idealizadas. Da educação às economias, passando pela ideia de "segurança da bala" que está já em atividade, regras estão sendo "recolocadas" nos lugares marginais literalmente. A economia está visando o mercado mundial e desesperando o cidadão e, do mesmo modo a educação está sendo levada ao grau máximo de mercantilização com o FUTURE-SE que está mais para um foda-se de quem mais precisa de educação pública no Brasil!
}

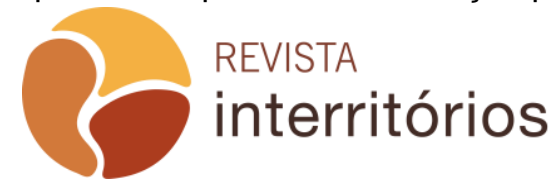

Interritórios | Revista de Educação Universidade Federal de Pernambuco, Caruaru, BRASIL | V.6 N.10 [2020] 
diferente (colonizado) das amarras/armaduras políticas: assistencialistas do Estado-Nação e das políticas corporativas das Grandes Corporações Privadas que homogeneízam os corpos das diferenças.

Pontos de origem e rotas de dispersão são conceitos chaves para traçar a geopolítica do conhecimento/ sensibilidade/ crença, tanto como a corpo-política do conhecimento/ sensibilidade/entendimento. Quando Frantz Fanon termina seu Pele negra, máscaras brancas com uma prece: Oh corpo meu, faz de mim, sempre, um homem que se interrogue! (1973, p. 192) expressou, em uma só frase, as categorias básicas da epistemologia fronteiriça: a percepção bio-gráfica do corpo Negro no Terceiro Mundo, fundando assim uma política do conhecimento que está arraigada assim como o corpo racializado, nas histórias locais marcadas pela colonialidade. Ou seja, um pensamento que faz visível a geopolítica e corpo-política de todo pensamento que a teologia cristã e a egologia (e.g. cartesianismo) ocultam. Portanto, se o ponto de origem do pensamento/sensibilidade e do fazer fronteiriços é o Terceiro Mundo, e se suas rotas de dispersão se realizaram através de quem migrou do Terceiro para o Primeiro Mundo, então o ser e o fazer, habitando as fronteiras, criou (sic) as condições para ligar a epistemologia fronteiriça com a consciência imigrante e, em consequência, desvinculá-la da epistemologia territorial e imperial baseada nas políticas de conhecimento teológicas (Renascimento) e egológicas (Ilustração). Como é bem sabido, as políticas teoy ego-lógicas do conhecimento se basearam na supressão tanto da sensibilidade como da localização geo-histórica do corpo. Foi precisamente essa supressão o que tornou possível que a teo-política e a geopolítica do conhecimento fossem proclamadas universais. (MIGNOLO, 2017, p. 16-17).

Levando em consideração esse cenário atual da arte e da educação em contexto de políticas brasileiro, caótico, diga-se de passagem: com fechamentos de exposições e espetáculos, limitação na atuação de agências de fomentos às artes; doutrinação e alienação políticas, cortes, militarização, tecnização e corporativismo empreendedor da educação pública - básica e universitária -, em que a política enquanto arma do Estado-Nação tem instalado o caos nas políticas de Arte e Educação no Brasil, este artigo quer, valendo-se do pensamento epistêmico descolonial fronteiriço como "método" investigativo, discutir ou mirar ideias de como podemos ainda nos enxergar, se possível for, em um momento de crise política. ${ }^{7}$

\footnotetext{
7 É preciso destacar que esta crise que trato neste artigo tem caráter político-partidário e não caráter artístico em crise como rupturas como o discutido por mim no artigo "Epistemologias fronterizas em arte e cultura periféricas: "paisagens" decoloniais através da arte" a ser publicado este ano na revista Temporal - prática e pensamento contemporâneos. Disponível em: https://periodicos.unb.br/index.php/temp/index.
}

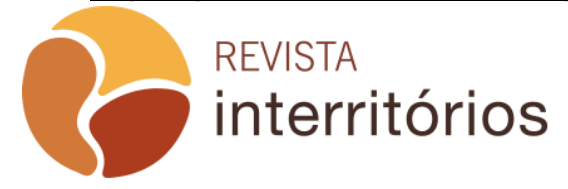

Interritórios | Revista de Educação Universidade Federal de Pernambuco, Caruaru, BRASIL | V.6 N.10 [2020] 
É no mínimo curioso observar hoje também que nosso atual momento político no Brasil, dada à condição de país que vive sob um "Estado democrático de direito" como opção política, que teve elegido em 2018 um dirigente que se mostrou muito radicalmente contra as diferenças culturais brasileiras: negros, indígenas, natureza, pobres, mulheres, gays, direitos políticos, à educação pública, entre muitas outras mazelas que sempre assolaram o Brasil. E é curiosa tal observação quando se constata agora, em pleno 2020, que quem o elegeu foi exatamente a mesma sociedade que se julga da família, cristã e que considera o direito dos diferentes uma premissa de vida. Por certo, então, pode-se afirmar que até o conceito de família em que essa sociedade está ancorada é hipócrita, sem dizer que o de caridade cristã e o de "dar" direitos ao diferente são falsos e o diferente está no desesperado que deve se submeter aos mandos do "bondoso".

Diuturnamente somos brindados (atacados) com novas declarações e ações desse governo em exercício que eleito por uma sociedade conservadora - do que não são os nossos princípios de formação: moral e bons costumes, menos ainda de raça, classe e gêneros iguais aos estabelecidos pelo projeto moderno europeu do século XVI; pior ainda que não contempla o capitalismo e acessos globalizados do projeto pós-moderno do século XIX - diz-se no dever de defender a família, as crianças e o conservadorismo pela nação. Esquece-se, portanto, o governo que atribui cargos e direitos de mandos a pessoas que exaltam até o nazismo, mas também o fascismo, o conservadorismo extremo, a pureza de raça, a padronização da fé, questiona inclusive avanços científicos e ressalta a improbidade dos diferentes que a sociedade brasileira é constituída exatamente de maioria do que ele odeia: inclassificáveis. Logo, temos então um governante que governa para a minoria ou temos na maioria da população um sentimento de pertença ao que nunca foi, é ou será!

Evidentemente, também, para tudo isso, reconheço que o Brasil, literalmente, está pegando fogo! Que a beleza de um(a) é melhor que a experiência de outro(a)! Que fritar hambúrgueres e vagar por montanhas em países estrangeiros quase garante o direito de representação do Brasil ao ente querido em nível internacional! Que até defecar menos se tornou norma impositiva para controlar ações incendiárias! Além de reconhecer que para tratar da questão que muitas outras certezas vistas e ouvidas nos últimos meses estão em torno da "política brasileira" atual, não somente de arte e educação, mas que ninguém parece perceber que em vias de tudo isso se constata que determinada tripa do intestino grosso do dirigente da política maior do país fora costurada ao aparelho fonador e por isso também ouvimos tanta merda em relação às políticas gerais/gerenciais no Brasil atual em todos os seguimentos. 
É certo, portanto, que no país, em todas as suas localidades, nos últimos doze meses houve uma crescente dos índices de feminicídios, queimadas (des)controladas, invasões de terras indígenas, exaltação de preconceitos raciais, quedas e ascensões de políticos (e oportunistas de diferentes classes operárias) e dirigentes de instituições cada vez mais extremistas, e, meu caso de experiência própria, distanciamentos entre familiares que têm nas gêneses de suas constituições todas essas diferenças prejudicadas por discursos de ódio, porque aqueles também elegeram um "autocrata" ao governo. Lógico que estou reconhecendo tudo isso agora, mas sabendo que todas essas características da perversidade cultural já faziam parte da tradicional família, cristã e boazinha brasileira. As mesmas atrocidades que estão hoje muito mais evidentes por causa da glorificação do governante em defesa delas, sempre estiveram contempladas sob os tapetes das casas das famílias do Brasil. Levantar os tapetes das salas nas casas brasileiras hoje é evidenciar uma história biográfica para além da colonialidade histórica: virão à tona mortes e estupros de mulheres desconhecidas, filhos gays e lésbicas assassinados ou internados em hospitais para loucos, e ainda pecados cometidos pela cristandade; problemas que as famílias sempre fizeram questão de acobertar.

Deste modo, quero discutir e pensar acerca das questões da existidura (BARROS, 1998) da arte, da educação e da política brasileiras em tempos atuais sem nenhuma pretensão político-partidária - seja de esquerda, centro ou de direita -, mas como professor do ensino universitário público brasileiro, em um curso de Arte de graduação e de Educação, em nível de pósgraduação, que devem prioritariamente formar cidadãos politizados crítico, social, econômico e culturalmente falando. Logo, não vou tratar neste trabalho de políticas de arte e de educação (de (des)políticas) que não atendem à corpo-política (MIGNOLO, 2008); corpo(s) que não quer(em) mais viver sob as jaulas do Estado ou das Corporações em prol de assistência precária (esmolas), como se ainda fossemos identidades modernas, ou sob a lógica de trabalhar para consumir, ter e sobreviver (construída no projeto pós-moderno) para o cidadão contemporâneo.

A política da identidade opera na suposição de que identidades essenciais entre as comunidades marginalizadas (por razões raciais, de gênero e sexuais) são as que merecem reconhecimento. Em geral, política de identidades não se compromete em nível de Estado e permanece na esfera da sociedade civil. Identidade em política, ao contrário, desligase da jaula de ferro dos "partidos políticos" como tem sido estabelecido pela teoria política moderna/colonial e eurocentrada. (MIGNOLO, 2008, p. 312). 
O mesmo é possível argumentar em favor da arte em política, educação em política, e da própria política em política e de corpos em política que consideram as diferenças culturais e coloniais e que, porque não contemplam o padrão de arte, educação, corpo e política modernos, não defendem partidos ou políticos e/ou ideologias político-partidárias em prol de políticas para si.

Assim, as discussões no trabalho acabarão por evidenciar, portanto, que estamos "vivendo" em um momento político no qual não há políticas públicas de arte, de educação, saúde ou de segurança sendo pensadas que não sejam ideologicamente políticas partidárias priorizando os discursos de manutenção de exclusão das diferenças mais clássicos: raça, gênero e classe, ancorados pela fé cristã, falantes de línguas oficiais e que têm a ciência moderna como única forma de gerar conhecimentos. Por isso a escola está sendo tornada técnica, impessoal e desumanizada, a arte não pode mais tratar de diferenças culturais, dirá então de diferenças coloniais, e as políticas voltam-se exclusivamente para os seus pares que têm identidades definidas pelos próprios sistemas que essas impõem. ${ }^{8}$

Igual, menos ainda podemos dizer que há, na atual conjuntura da política no Brasil, políticas de identidades que estejam sendo pensadas para contemplar as diferenças das pessoas que precisam se ver em políticas públicas: os indivíduos das chamadas minorias que precisam, na lógica de direitos e democracia para todos em um país laico, miscigenado e que reconhece suas diferenças sociais, serem incluídos em políticas que possibilitam a esses acessarem às "coisas" que lhes foram retiradas/impossibilitadas; tanto pela conservação de um histórico colonial, caso do Brasil e de países da América Latina, tanto quanto pela regra contemporânea em que a arte e a educação devem construir operários para trabalhar, consumir, ter e sobreviver. Essa última lógica, portanto, sob o domínio do estado-nação em favor das corporações capitais, está promovendo todos os dias mais a ideia de querer ter sobre a de querer ser. Depois das últimas reformas da previdência brasileira, até o regime previdenciário no Brasil enfrenta problemas, para o contribuinte, para acessá-lo. Quase dois milhões de brasileiros lutam hoje e enfrentam uma fila virtual para conseguir o benefício do INSS em diferentes situações de necessidades. Antes, benefícios que eram liberados em tempo recorde, hoje têm cidadãos com quase dois anos de espera para conseguir serem atendidos na burocracia do sistema de

\footnotetext{
8 Tais fatos aqui devem ser vistos como verídicos uma vez que vimos, nos últimos meses, uma luta entre as próprias forças dominantes da situação política atual em prol de seu lugar ao sol. Uma troca de xingamentos, ofensas desmedidas em rede nacional de televisão - ou medidas, já que esses sabiam exatamente com quem se misturavam - para defender um lugar na hierarquia do poder que se construiu à base de muito ódio, rancor e vontade de poder contra os mais fracos que são maioria do país. Do mesmo jeito, há uma defesa de um conservadorismo que as políticas brasileiras nunca fizeram questão de vivenciar na prática, porque sabemos que nos bastidores - tira ministro, põe ministro, diminui poder, aumenta poder, entre outras coisas - é questão de opção político-partidária.
}

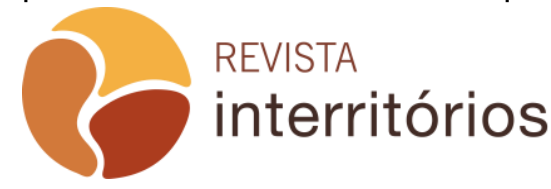

Interritórios | Revista de Educação Universidade Federal de Pernambuco, Caruaru, BRASIL | V.6 N.10 [2020] 
assistência ao desempregado, mãe-recente, aposentado, "encostado", beneficiário de várias categorias no Brasil.

Quer dizer, temos diferentes processos de apolíticas ((des)políticas) para a corpo-política - esses corpos todos que não conseguem e que estão sendo impedidos de se verem pela falta de tudo na arte e na educação atuais: histórico que faz a manutenção de exclusão daqueles que não contemplam as categorias moderna de gente; e processos contemporâneos que insistem em reforçar que sem emprego, o que não pode atender ao emprego porque tem o corpo deficiente/deformado (na lógica dos centros), o indivíduo que não estudou/estuda, entre outras categorias classificatórias capitalistas de eliminação/desclassificação daquele que é tornado improdutivo/descartável. Mas também não temos atendidos todos os outros corpos das diferenças do padrão hegemônico de ser-corpo. Assim, o indivíduo não pode ser contemplado pelas políticas que aí estão sendo mancomunadas. Ao certo, portanto, torna-se impossível se ver em política qualquer em tempos (bolsominions) atuais.

Por conseguinte, há, nas políticas brasileiras, a manutenção do conceito de "outro" construído pelo europeu (que é o Eu) erigido a partir do século XVIII, mas exaltado nas culturas ocidentais a partir do século XVI, com arquitetura desde o século XVIII, com a ideia de colonização/homogeneização dos bárbaros a fim de civilizá-los levando a cabo a salvação da alma como a "salvação do corpo" por meio da adesão (submissão) à cristianização. E essa manutenção dá-se ainda hoje graças ao vínculo das políticas públicas econômicas e de segurança voltarem-se cada vez mais para internacionalização do país comercialmente falando, mas a arte, a educação e a própria política não estão fora. $E$ tal fato acaba por promover as mesmas intenções na educação que, do mesmo modo, altera a arte, a política de saúde e as outras políticas que são des-ações "afirmativas" de um Estado que cobra para ofertar um serviço mal e porco. Falta de vacinas ao direito de cultura e aposentar-se por aqui. Ao certo, portanto, não podemos falar de política de arte e em política de educação atuais porque essas não levam políticas às identidades em políticas, mas sim que prestam um desserviço sob o rótulo de políticas de identidades.

\section{Destecendo a teia da ideia de política brasileira}

Do ponto de vista da epistemologia ocidental e da teoria política, o colonialismo é um mero derivado, um processo desagradável, mas necessário para construir um mundo melhor. É precisamente o que foi escondido e sem nome por trás das três ideologias aceitáveis [o conservadorismo, o liberalismo e o socialismo] e a face visível do império, que cobria as colônias e as 
transformou em entidades marginais no espaço e no tempo. (MIGNOLO, 2007, 105). ${ }^{9}$ (Tradução Livre minha).

Desde meados de 2017 as artes no Brasil vêm sofrendo ataques furiosos contra a exposição de determinados assuntos e temas que estavam em franca evidência na cultura contemporânea até então. ${ }^{10}$ Mas, ao contrário do que muitos pensam, as artes nunca estiveram na totalidade favoráveis aos discursos que delimitam a atuação da própria arte. Do mesmo jeito é possível dizer que nem todas as obras artísticas no mundo, de diferentes tempos e lugares, estiveram em discordância aos discursos que validaram, financiaram, empreenderam e excluíram e incluíram artistas no sistema que hoje reconhecemos como "circuito das artes". Mas é evidente que não quero tratar, ao menos por ora, desta questão de opção em prol ou contra discursos por escolha do artista ou da sua produção em arte.

Até mesmo porque não discordo ou condeno o artista ou as obras artísticas e membros de um sistema da arte que se favorecem dos discursos dos poderes para produzir ou situarem-se no circuito, mas, lógico, desde que esses reconheçam a sua submissão "poética", a famosa "estética" em favor de um padrão ou o seu "estilo formal" dos trabalhos a favor do comércio e submissão à crítica desses. Pois, diferente disso, é impossível não discutir em que medida os trabalhos artísticos e artistas ou a produção de conhecimento por meio da arte (educação) não estão se vendendo para fazer manutenção de (des)políticas de arte, de cultura e de produzir conhecimentos. Afinal, poucos frequentam as rodas dos circuitos das artes grassados nos editais que contemplam àqueles que são eleitos pela crítica que são também mantidos pelo estado-nação ou pelas corporações de colecionadores (que lavam dinheiro) comprando arte.

Do mesmo jeito quando falamos da educação no Brasil é preciso recordar que documentos ou leis - federais, estaduais ou municipais - sempre definiram a constituição do sistema de ensino, a formação do professor e o trabalho docente nas escolas e nas universidades. Mais especialmente quando falamos do Ensino de Arte, antes dos documentos tivemos uma série de critérios políticos diferentes que delimitaram os modos de ensinar arte, ensinar através da arte ou usar da arte para formar indivíduos para diferentes finalidades. Da chegada dos colonizadores para cá, até meados dos anos

\footnotetext{
9 "Desde el punto de vista de la epistemología y la teoría política occidental, el colonialismo es un mero derivado, un proceso desagradable pero necesario para construir un mundo mejor. Es precisamente lo que ha quedado oculto y sin nombrar tras las tres ideologías aceptables [el conservadurismo, el liberalismo y el socialisrno] y la cara visible del imperio, que cubrió las colonias y las convirtió en entidades marginales en el espacio y en el tiempo" (MIGNOLO, 2007, 105).

1010 No texto "As fronteiras que es—m as produções culturais da exterioridade" (2018) discuti exposições impedidas/barradas por "ditaduras" já no século XXI até em meu contexto local.
}

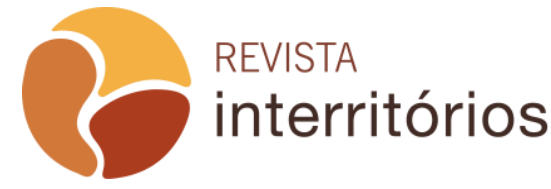


1980 no Brasil, a educação de/em/com arte esteve conduzida por políticas diferentes que sustentassem as aparências da colônia como lugar culturalmente desenvolvido ou em desenvolvimento. É certo que fomos modernizados de uma hora para outra para deixarmos de viver sob as brumas do império, tornados pós-modernos em prol das demandas políticas capitalistas para, enfim, nos percebermos como indivíduos contemporâneos (me pergunto até hoje de quê e de quem?).

Nesse sentido, [até hoje] as disciplinas mais tradicionais nas escolas tendem a fazer uma uniformização dessas práticas culturais e, consequentemente, de seus alunos, os praticantes das culturas consideradas menores. E tudo em nome de um currículo, de um programa, de um conteúdo ou script a ser seguido. (BESSA-OLIVEIRA, 2010, p. 81).

A educação brasileira molda aos professores na universidade, nos cursos de graduação e de pós-graduação, que seguem moldando os corpos dos estudantes nas escolas da educação básica. Pois, no caso do professor de Arte, se esse é modelado a aprender que há um currículo específico de arte, normalmente histórico e geográfico europeus, que elege padrões de qualidade (Renascentistas, normalmente) que devem ser reverberados ad eternum nas aulas, e se ele dá nas suas aulas maior importância apenas para as culturas ocidentais, é certo que esse mesmo professor vai reproduzir esse discurso que impotencializa a arte, as culturas e os conhecimentos que são produzidos pelos estudantes que, então, passam a não ter corpos (são impotentes e deficientes) próprios. Assim, nossas políticas de educação não são, igualmente, educação em política que potencializam corpos-política para a vida em sociedade.

Mas também não é da educação enquanto ato de obediência política que quero levar à baila neste trabalho. Pois, da ótica que vou preferir discutir as artes e a educação, essas não obedecem em totalidade às políticas, ou ao menos não o deveriam obedecer para existirem enquanto arte e educação em política. Ou seja, arte e educação em política têm como pressuposto mínimo resistência aos sistemas que impõem determinadas regras, por exemplo, de educar para trabalhar ao invés de construir conhecimentos para que forme indivíduos críticos aos contextos nos quais estão inseridos. Do mesmo modo a arte tem como ato em política o dever de reivindicar re-existência contra tudo e todos que determinam e delimitam a atuação do fazer artístico e, igualmente, do ensinar e pesquisar através ou por meio da arte. Isso sim está relacionado àquela ideia histórica de que arte, educação e política devem ser politicamente indissociáveis. 
Em primeiro lugar, e também o início irrecusável de toda a reflexão e atuação nessa direção, para tornar visível e irrefutável de que não há "pedagogia" às cegas, pois, a pedagogia sem modificador é uma pedagogia oficial, em serviço do sistema político e econômico que a sustenta, promove-a e também a deixa cair em favor de ocupações mais "eficientes". (MIGNOLO, 2014, p. 9). ${ }^{11}$ (Tradução livre minha).

Uma segunda questão que inviabiliza pensar em existência de políticas da arte e da educação, por conseguinte dos próprios indivíduos que carecem de políticas neste momento é porque as políticas estão retrocedendo os avanços alcançados e não estão para a arte e a educação como políticas de construção de possibilidades para tod@s. Quero dizer, ao invés de termos políticas sociais - de arte, de cultura, de educação, saúde e até de políticas efetivas de segurança pública - estamos recebendo enfrentamentos contrários e diários às situações que sujeitos em condições que deveriam receber assistências estatais e/ou privadas, via políticas públicas, são desprezados. Vemos, com tudo o que têm ocorrido nos últimos desses meses de desgovernança, que o Estado e as Corporações se juntaram, balizados até pelos Três Poderes, em alguns casos, para fazer valer a ordem e a repressão [do conservadorismo, do liberalismo e do socialismo] para poder desconsiderar as mazelas sociais dos necessitados e fazer valer o poder autoritário sobre as diferenças. Logo, as políticas de arte e de educação atuais (até a BNCC com tão "boa vontade" pensada) não se voltam para construir cidadãos críticos, mas alienados e ideologicamente políticos para dominação.

\begin{abstract}
A Base Nacional Comum Curricular (BNCC) é um documento de caráter normativo que define o conjunto orgânico e progressivo de aprendizagens essenciais que todos os alunos devem desenvolver ao longo das etapas e modalidades da Educação Básica. Aplica-se à educação escolar, tal como a define $0 \S 1^{\circ}$ do Artigo $1^{\circ}$ da Lei de Diretrizes e Bases da Educação Nacional (LDB, Lei $\mathrm{n}^{\circ}$ 9.394/1996), e indica conhecimentos e competências que se espera que todos os estudantes desenvolvam ao longo da escolaridade. Orientada pelos princípios éticos, políticos e estéticos traçados pelas Diretrizes Curriculares Nacionais da Educação Básica (DCN), a BNCC soma-se aos propósitos que direcionam a educação brasileira para a formação humana integral e para a construção de uma sociedade justa, democrática e inclusiva. (BNCC, 2017, p. 7). (Grifos do texto).
\end{abstract}

11 "En primer lugar, y también el irrecusable comienzo de toda reflexión y actuación en esta dirección, en hacer visible e irrefutable que no hay "pedagogía" a secas puesto que la pedagogía sin modificador es una pedagogía oficial, al servicio del sistema político y económico que la sustenta, promueve y, también, la deja caer en pro de ocupaciones más "eficientes"'” (MIGNOLO, 2014, p. 9).

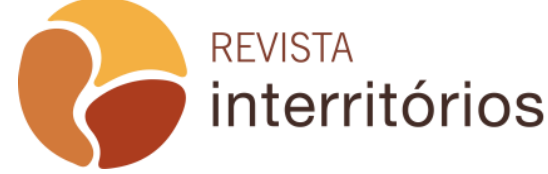

Interritórios | Revista de Educação Universidade Federal de Pernambuco, Caruaru, BRASIL | V.6 N.10 [2020] 
Antes de tudo é bom lembrar que a BNCC (2017) foi construída sobre uma base de muitas controvérsias em que sequer as demandas da sociedade especializada na educação para a construção de um texto que regula a educação básica foram ouvidas quando, na verdade, todos os posts feitos por esses especialistas nos debates sobre a construção daquele texto foram usados (contra) para aprovar um texto que não foi devidamente discutido com abrangência igual para ambos os lados: Estado e sociedade. Agora, em 2020, já implantada a Base Nacional Comum Curricular o MEC estabelece, por meio de um outro documento já aprovado pelo CNE - Conselho Nacional de Educação (2019) - no último sete de novembro, diretrizes gerais sem discussões devidas para a formação de professores para atuação na educação básica. Logo, estabeleceu-se aí também uma política de educação sem corpo: uma política que não toma para sua construção as corpos-política da sociedade.

Mas de bondade até o inferno está cheio, portanto, ocasiono no debate a questão que me é maior que trata das políticas de arte e de educação atuais como (des)políticas às corpos-política que são expostas como políticas que não têm corpo por desconsiderar os corpos que mais precisam de políticas. Corpos neg(r)ados na arte e na educação (FARIA; BESSA-OLIVEIRA, 2019), por exemplo, mas de muitos outros corpos das diferenças coloniais que as políticas atuais deveriam continuar priorizando para serem classificadas como políticas públicas, mas antes como efetivas às infindáveis necessidades dos corpos sem existência no contexto atual brasileiro. Ou seja, os corpos que são desconsiderados nessas políticas de cortes e discriminação (interior no Brasil, das Humanas, não-binários, não-cristãos, não-brancos e não-falantes das línguas oficiais) vão ficar cada vez mais invisíveis porque não poderão continuar acessando ao sistema, já muito precário até então, de bolsas, estruturas escolares e artísticas, e pior, agora em nível também federal que foi até aqui menos negativo que os demais níveis.

Como é bem sabido, as políticas teo- e ego-lógicas do conhecimento se basearam na supressão tanto da sensibilidade como da localização geo-histórica do corpo [da diferença]. Foi precisamente essa supressão o que tornou possível que a teo-política e a geopolítica do conhecimento fossem proclamadas universais. (MIGNOLO, 2017, p. 17).

Ao certo, se as políticas teo e geo-lógicas foram baseadas na supressão da sensibilidade das diferenças pela localização geo-histórica para estruturação do padrão de corpo que é europeu, nada nos impede de afirmar que essas mesmas lógicas cristã e geográfica continuam insistindo e, agora ainda mais reforçadas pelo suposto peso da história, que definem as "políticas" de arte e de educação no Brasil. Antes porque as ideologias religiosas que 
interferem no país que tem base cristã estão sendo a "testa de ferro" para empurrar ladeira abaixo as diferenças que não são percebidas em prol da defesa daquele modelo de família, por exemplo. Logo, também são as geografias e as histórias europeias e estadunidenses que estão, cada dia mais, reforçando a estruturação de políticas que atendem ao desenvolvimentismo capitalista e menos às necessidades corpóreas dos corpos sensíveis invisíveis brasileiros.

Se parece estranho lançar mão dessa afirmativa para pensar que a arte e a educação não têm políticas em seu favor porque estariam amarradas a teo e ego-lógicas políticas, o que gera a invisibilidade dos sujeitos das diferenças religiosas e locais, por exemplo, é porque constato que exatamente a teo e a ego-lógicas estão levando às atuais políticas a se portarem como ponto principal para excluir o diferente. Assim, é evidente que o não reconhecimento de corpos não-brancos, não-héteros, não-ricos que está sendo promovido pelas próprias políticas que estão sendo anunciadas, dia a dia, pelos diferentes órgãos federais, estaduais e municipais, são as que deveriam defendê-los através de políticas públicas de Estado. Pois, ora um, ora outro, em Mato Grosso do Sul também estamos tendo enfrentamentos contra a arte, a educação, a cultura e a produção de conhecimentos que não são classificados dentro dos padrões das políticas partidárias em evidência como se fossem políticas públicas. ${ }^{12}$

Por exemplo, a seleção e aprovação de acompanhantes para estudantes com necessidades especiais na educação básica municipal sem a devida formação específica em substituição à contratados especialistas foi a última (meados de 2019) providência tomada pelo prefeito de Campo Grande, capital de MS, para baixar a folha de pagamento da prefeitura. ${ }^{13}$ Já no âmbito estadual, também na educação, em Mato Grosso do Sul tivemos autorizado recentemente a capelania nas escolas a fim de "sanar" os problemas de violência, carência familiar, falta de crença espiritual e sociabilidade dos estudantes que dão problemas nas escolas. Já em nível federal é impossível listar a última ação dos órgãos competentes que menos esteja inviabilizando a educação ou a arte, já que esta tem relação direta com aquela, dada à quantidade dessas ações impositivas e de cortes que proíbem/coíbem o reconhecimento dos diferentes nas políticas nos últimos meses através de

\footnotetext{
${ }^{12}$ Em Mato Grosso do Sul rege a política do agronegócio: o Estado é responsável por grande parte da produção de grãos e gado exportados do País, produções que estão nas mãos de latifundiários políticos, coronéis e poucos milionários que "governam" as arte, a cultura e a educação à base da Lei do 44 .

${ }^{13}$ Providência já contestada pela Defensoria Pública de Mato Grosso do Sul que foi à Justiça para impedir que a Prefeitura de Campo Grande substitua os profissionais de apoio pedagógico por outros profissionais sem a mesma qualificação, chamados de assistentes educacionais inclusivos.
}

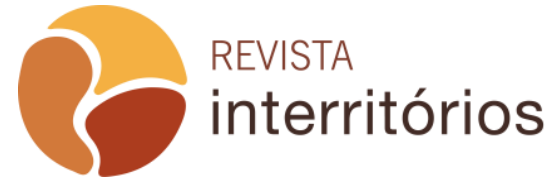

Interritórios | Revista de Educação Universidade Federal de Pernambuco, Caruaru, BRASIL | V.6 N.10 [2020] 
(des)políticas para as corpos-política como se fossem melhores políticas. A lista é devera enorme!

Uma merda atrás da outra e dita todos os dias e horários nos meios de comunicações brasileiros, com repercussões internacionais, pelo dirigente do país que, sem nenhuma autocensura por causa de horário ou uso de determinados termos inadequados, diz tanto defender a família cristã. De palavras de baixo calão a defesas de coisas que deveriam ser indefensáveis por alguém que dirige uma nação das diferenças divergências (como boas) como o Brasil, que não se dá o mínimo pudor de concentrar-se em formular termos e políticas de usos melhores que as que saem de seu canal de fala e do "seu" sistema de governo, vivemos atualmente uma (des)política seguindo a outra em fila indiana que contemplam, no mau sentido, as diferenças culturais e coloniais brasileiras. Todos os dias assistimos aos ministros e ao digníssimo líder brasileiro proferirem uma "parábola" cada um de merdoso maior.

As corpos-política, corpos diferentes das diferenças culturais e coloniais que contemplam a sociedade brasileira, precisam re-virar-se contra esse sistema que deforma e desumaniza os corpos sociais. É preciso empoderarse contra tudo e todos que lutam e lutaram para a situação dessa política partidária hoje em evidência no Brasil. Fazendo valer a corpo-política como ato de revisão dessa lógica do corpo hétero, branco e de classe alta, as diferenças podem promover a re-existência de corpos que foram sendo desconsiderados para a construção daqueles corpos coloniais como melhores. Bem como essas corpos-políticas podem instituir o corpo (sem padrão) qualquer como o corpo da hora e da vez no Brasil. Precisamos, urgentemente, reverter esse cenário inclusive dentro das casas brasileiras não naquelas de padrão de famílias, de fés e de direitos e de democracias falidas -, mas nas diferentes, divergentes e múltiplas casas que se erigiram contra todos os sistemas imperantes em vigência.

Por isso, é essencial, no nosso caso, projetar a concepção que norteia essas investigações, a fim de limitar o lugar de enunciação a partir do qual geramos nossas análises, nossas interpretações e nossas práticas. A partir do momento em que entendemos que qualquer construção conceitual sobre a sociedade é o resultado de uma instância reflexiva baseada nas características, conflitos, convergências e contradições de sociedades específicas e que estas estão localizadas, escolhemos aqui para orientar o olhar do ponto de vista a partir da perspectiva da opção descolonial e de sua concepção geo e corpo-política da construção do poder. 
(PALERMO, 2014, p. 21). ${ }^{14}$ (Tradução livre minha) (Grifos meus).

Situando o corpo e o lugar de enunciação entre as "fronteiras" de Mato Grosso do Sul, por exemplo, para gerir as articulações da corpo-política, é privilegiar lugares e corpos marginalizados, alocados na exterioridade colonial ao pensamento de interioridade moderno e da colonialidade do poder pósmoderno, para fazer gerir políticas de arte e de educação outras que contemplam exatamente àqueles corpos e lugares que nunca foram lembrados. E fronteiras nestes casos, vale reforçar, não estão para lugar geográfico exclusivamente de divisas de estados ou de nações, mas em lugares e corpos epistemológicos promotores de conhecimentos que não são reconhecidos pelos corpos e lugares que estabelecem os poderes até então. Portanto, uma construção conceitual de base descolonial precisa urgentemente e é indispensável para provocar a derrocada de políticas partidárias que sustentam o "Eu" como única lógica para promoção das políticas públicas que devem reverter às situações impostas de abandono, injustiças e injurias contra as diferenças (os outros).

Logo, a construção social de que existe um corpo-modelo situado em um tempo e lugar específicos, que cobria as colônias e as transformou em entidades marginais no espaço e no tempo, sobre os vários corpos e lugares supostamente inferiores é uma arquitetura imperante ainda nas próprias políticas do Estado-Nação a fim de reverter o dever desse em direito "para" aqueles. Assim, e não poderia ser de modo diferente, há uma divergência e a exposição conflitiva de ideias e ideais, muitas vezes ancorados em ideologias também opostas, que geram divergências onde deveria haver convergências em prol do bem-estar social. Não é outrem, portanto, a representatividade desse indivíduo que lidera o país que tem bases preconceituosas, discriminatórias e rancorosas em relação ao pobre, ao negro, ao indígena, à mulher, ao gay e à lésbica, a todas as diferenças culturais e coloniais que contemplam a formação brasileira ainda que a contragosto desses muitos que o elegeram.

Portanto, essas reflexões estão localizadas e impregnadas no meu próprio corpo que está bio-geo-grafado no contexto atual de Mato Grosso do Sul, ainda que com todas as suas divergências e convergências (políticas, culturais e artísticas), mas um corpo biogeográfico (que é, senti, sabe e faz);

\footnotetext{
14 "Es por ello que se hace imprescindible en nuestro caso diseñar la concepción que guía estas indagaciones, con la finalidad de acotar el lugar de enunciación desde el que generamos nuestros análisis, nuestras interpretaciones y nuestras prácticas. Desde el momento en que entendemos que toda construcción conceptual acerca de la sociedad es el resultado de una instancia reflexiva que se afinca en las características, conflictos, convergencias y contradicciones de sociedades concretas y que éstas se encuentran localizadas, se opta acá por orientar la mirada desde la perspectiva de la opción decolonial y su concepción geo y corpopolítica de la construcción del poder" (PALERMO, 2014, p. 21).
}

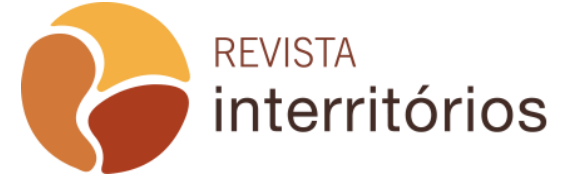

Interritórios | Revista de Educação Universidade Federal de Pernambuco, Caruaru, BRASIL | V.6 N.10 [2020] 
meu corpo que tem história e memórias vindouras das minhas idas e vindas dos lugares, inclusive de onde e ao lado de quem nasci, cresci e pensei ilusoriamente durante muito tempo que poderia ser. Assim, essas reflexões se orientam por uma opção descolonial como opção de vida, uma vida com Edgar Nolasco como meu companheiro de vivências e experiências (experivivências) e junto dos meus quatro cachorros atuais (o Barão, o Tom, a Tica que é a minha Frida Kalo e a Katharina Brunilde que na nossa concepção descolonial fronteiriça é a Nega). Portanto escolhi e escolho para os corpos e lugares das exterioridades políticas que têm concepções geopolítica e corpo-política das diferenças.

Pensar e agir descolonialmente são as únicas alternativas que temos em um momento que gera tão grande invisibilidade do diferente. Logo, descolonizar torna-se a única forma de ainda nos enxergarmos neste momento de crise da própria política em que ser diferente tornou-se um problema já que as políticas estão priorizando as paridades partidárias. Assim, é preciso lutar contra a tecnização e militarização da educação pública e até privada. Pois essas vão impedir, por exemplo, o corpo trans reconhecer-se nos espaços das escolas; vão impedir cabelos "não comportados" viverem livres sem amarras e/ou alisamentos; vão proibir e coibir a prática de qualquer outro ato de fé que não seja da matriz cristã; vão impedir, igualmente, de a mulher ter o direito de ter direitos assim como qualquer homem; entre muitas outras coisas previstas na Constituição de 1988 ou na LDB - Lei № 9.394, de 20 de dezembro de 1996 - que estão sendo retiradas como se fossem obrigações das políticas públicas atenderem apenas quem contempla aqueles padrões contrários a esses das diferenças. Há em construção um novo fascismo em pleno País onde as novas direitas extremistas não deveriam ter lugar de ascensão.

A epistemologia fronteiriça e a descolonialidade seguem de mãos dadas. Por quê? Porque um dos objetivos da descolonialidade é transformar os termos da conversa e não só seu conteúdo. Como funciona a epistemologia fronteiriça? (MIGNOLO, 2017, p. 17).

É nos reconhecermos indivíduos descoloniais. Indivíduos que reconhecemos que não somos reconhecidos pelas políticas de Estado em construção que desqualificam tudo e tod@s que não contemplam a lógica cartesiana de produção de conhecimentos, que não contempla o corpo masculino ou binário, que não tem fé cristã e que é um corpo que não apenas se comunica através de línguas e linguagens não reconhecidas como línguas oficiais. Precisamos ir às ruas e nos fazermos reconhecidos como corpos em políticas! O latino é um povo que fala com o corpo que si-move-se (BESSAOLIVEIRA, 2018a). Como corpos que contrapõem a lógica de crescer para 
estudar, para trabalhar e poder consumir e assim ter para atender à sociedade do consumo capitalista que controla a todos e todas através da subjugação do outro ao trabalho de 12 horas diário, à moradia financiada, ao carro pago em prestações por mais de cinco anos (precisamos inverter o querer ter para querer ser novamente), contrapor à ideia de corpos comportados por corpos que movimentam. Como se não existisse outra lógica possível que não a de aprender as línguas oficiais (especialmente inglês, francês, alemão, italiano, espanhol) para sustentar o mercado de dependência das culturas periféricas em prol das culturas hegemônicas até por meio da língua.

Assim, não nos deve servir mais aquelas políticas de arte e de educação, como apoio a essas ou à falta desse apoio à arte e a educação, que na verdade sempre foram fálidas porque têm como ato primeiro a primazia da antiguidade de que a arte e a educação devem estar sub judice das políticas do Estado, de Corporações ou de determinadas famílias abastadas para terem a aprovação de circulação e condução de um conhecimento específico para aceitação desses que estabelecem os padrões coercitivos ainda hoje. Logo, aquelas políticas públicas que até então (fins de 2018) ainda estiveram presentes no Brasil, se não negaram as diferenças culturais como o fazem as novas (des)políticas bolsominians - já que essas atuais nem podem ser reconhecidas como prováveis políticas públicas que são pensadas para o público - e também não reconheceram as diferenças coloniais, agora é impossível dizermos que há a efetiva elaboração de políticas públicas que querem atender e reconhecer sequer àquelas diferenças culturais de dantes enxergadas. Agora, as relações antigas entre arte versus política, política versus educação e políticas versus políticas hoje se dão minimamente como partidárias aos seus próprios pares parentais.

Em tempos remotos (nos períodos clássico e moderno) essas relações de artes versus as políticas de Estado ou com as Corporações eram ancoradas apenas em exposição desse ou daquele artista ou trabalhos artísticos, e até em vários casos na exaltação do poder que adquiria a produção. ${ }^{15}$ Ainda eram coisas aceitáveis. Mas agora, de janeiro de 2019 para cá, as relações de arte versus política, arte versus religião, arte versus educação, de arte versus sistema da arte, arte versus arte e até política versus política têm peso marginal: ora mata-se para sobressair-se, ora você é morto para não ser evidenciado. O Estado-Nação que defende o uso da arma de foto ou a força truculenta contra as diferenças não está disposto a conversar para a promoção da convivência entre os diferentes. Diuturnamente somos colocados em

\footnotetext{
${ }^{15}$ Aqui estou lembrando exclusivamente das relações entre os Mecenas, o Papado Católico e dos Reis com artistas multitécnicos que imperaram no período clássico (até o prémoderno) (do período Bizantino aos fins do Renascimento -11 de maio de 330 d.C. ao final do Rococó por volta dos anos 1700, respectivamente) e das grandes instituições museológicas e artistas que se estabeleceram na modernidade após princípios do século XIX.
} 
estados de alertas para lutar pela nossa sobrevivência em um espaço onde um corpo (vida) vale muito menos que um dólar americano ou um euro. Menos ainda vale em relação ao Grande Eu.

A coisa agora é bem mais séria! Estamos tendo em evidência, cada dia mais, políticas de desmonte da arte e da educação em construção o tempo todo. Ora temos impedidas a circulação, exposição da arte e agora até a filmagem de obras que tratem das diferenças que nunca foram contempladas nas políticas públicas brasileiras de forma satisfatória. Temos também a luta diária de partidos de extrema-direita da efetivação de projetos "contra o direito de liberdade de ensinar" - os chamados "Escola Sem Partido" e "Escola Sem Religião" - que na verdade pregam a ideologia de perspectivas restritivas de partidos políticos e religiões específicas nas escolas públicas. Até um Gibi é impedido de circular porque a prefeitura sob o cetro pastoral de Marcelo Crivella no Rio de Janeiro simplesmente definiu que a ilustração em quadrinhos de um beijo entre homens é "conteúdo sexual proibido para menores" em "circulação livre" sem rotulação; que na verdade é ato de ataque ao pudor, à moral e aos bons costumes do padrão de família moderna do religioso que se diz agora também político da família brasileira. ${ }^{16}$

Na verdade, atuações político-religiosas como as que estão na linha de frente das atuais políticas partidárias brasileiras estão reforçando os elos antigos de fraternidades, familiaridades, hospitalidades, amizades, religiosidade, hostilidade em relação aos diferentes, entre muitas outras questões, para imposições de políticas que são apolíticas que determinam limites para existência dos diferentes. Padrões parentescos que reforçam a manutenção da linhagem consanguínea, branca, de origem nórdica, masculina, falante de línguas oficiais, por mais que não saibam sequer escrever ou falar, predileção de atendimento sempre aos seus familiares e recepção de braços abertos aos sistemas que supostamente são iguais, mas estão sempre querendo "sempre mais" dos oprimidos, relações de amizades e de religiões para sustentar as políticas atuais estão provocando repressões políticas às pessoas diferentes e das diferenças. Logo, são práticas que estão levando à crise atual, na arte e na educação que não têm mais direito de livre atuação e é também igual na própria política que não tem função efetiva de ação de política pública social. Tudo por causa de políticas partidárias ideológicas de extrema-direita que não se veem como políticas de restrição/seleção ao que não tem ideologia igual.

\footnotetext{
${ }^{16}$ Sobre este "último" ato de coerção conferir aos sites de notícias para ver a verdade por trás da ideia de preservar as crianças brasileiras que sequer têm escola descente. Cf.: https://www1.folha.uol.com.br/ilustrada/2019/09/marcelo-crivella-manda-censurar-gibis-dosvingadores-na-bienal-do-livro-no-rio.shtml. Acessado em: 07 ago. 2019. No caso do Rio de Janeiro as crianças estão sendo mortas à bala de fuzis dentro das escolas.
}

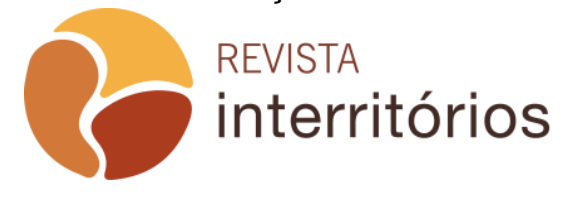

Interritórios | Revista de Educação Universidade Federal de Pernambuco, Caruaru, BRASIL | V.6 N.10 [2020] 


\section{Considerações de arte, educação e políticas em política}

Ao certo, não é segredo para ninguém que as atuações das políticas brasileiras, nos vários níveis hierárquicos hoje, em que a política está sendo utilizada enquanto arma de poder do Estado-Nação (através do uso até do tacape pré-histórico por um "comandante" alienado e que acha que pode levar as coisas a mãos de ferro), têm instalado o caos onde deveria haver políticas de Arte e de Educação, mas também de cultura, de produção de pesquisas, políticas de segurança pública sem arma e sem bala, políticas de saúde e muitas outras pelas quais pagamos (muito caro e não somos resguardados devidamente) no Brasil para atender aos indivíduos diferentes que precisam dessas políticas para recuperar o tempo e direitos que lhes foram usurpados. Além de promover a recuperação da dignidade das pessoas que nunca tiveram esse direito. Assim, ainda que pareça que não temos alternativas diante de um discurso ditatorial-fascista-extremista em franco processo, que simplesmente não se vê enquanto tal, a estratégia é pensarmos em como discutir ou elaborar ideias de como podemos ainda exigir que para a elaboração das políticas públicas no Brasil é (extremamente) preciso enxergar as diferenças, seja à custa de quantos corpos precisarem e mesmo do que for necessário, em qualquer que seja o momento de política no País.

Precisamos sim, como já advertiu Paulo Freire faz muito tempo, de uma educação democrática, libertadora, ou como tem reforçado Walter Mignolo, de uma pedagogia que educa a própria escola e que educaria o político: "Assim, a tarefa da pedagogia descolonial consistirá, paradoxalmente, em educar a escola, uma vez que a escola já foi desescolarizada" (MIGNOLO, 2014, p. 9) ${ }^{17}$ (Tradução livre minha) porque esta instituição, como está hoje, é a favor do Estado-Nação ou das Corporações que ainda a vêm como ineficiente porque sequer atende àqueles. A escola, na perspectiva política atual, deve ser militarizada para (de)formar corpos que obedecem e não desrespeitam e que menos ainda pensem; deve dar formação técnica para impor o trabalhar e produzir em vias de atender ao mercado do trabalho das corporações que estão nas mãos das mesmas políticas que instituem o trabalho como "direito à liberdade" por trás do dever de produzir para sobreviver. Do mesmo jeito, as (des)políticas atuais de educação estão reforçando uma escola que forma cidadão alienados, desinformados, acríticos, religiosos ortodoxos e imbecis aptos ao trabalho quase escravo que acham que têm direitos reconhecidos graças ao rótulo de conservadorismo da família brasileira cristã. "Fui e continuo conservadora': [é] o que pensa Regina Duarte, [nova provável Secretária de Cultura] que fará 'teste' no governo Bolsonaro" assumindo lugar

17 "Así las cosas, la tarea de la pedagogía descolonial consistirá, paradójicamente, en escolarizar la escuela puesto que la escuela ya sido desescolarizada" (MIGNOLO, 2014, p. 9). 
daquele que deu crédito a um discurso nazista - Roberto Alvim -, exonerado no dia 17 de janeiro de 2020, após usar da "coincidência retórica" como defesa da barbárie. ${ }^{18}$

Compartilhando essas críticas, duvido que apenas a educação possa resolver a desigualdade. Ainda menos quando essas políticas não são acompanhadas por profundas transformações de conhecimento, metodologias e propósitos. Assim, por exemplo, aumentar as matrículas escolares por si só, [...] [militarizar, tecnicizar ou impor políticas capitalistas e religiosas] não implica que mudanças estejam sendo feitas no funcionamento social que resultem em maior simetria; o mesmo se aplica à alfabetização das comunidades argentinas originais em seus idiomas, [...] não contribuirá para a descolonização e a interculturalidade [passar a falar inglês, por exemplo]. Sem dúvida, é necessário mudar o conteúdo, as línguas, os termos da conversa, mas também para transformar a disposição do poder, esta é a colonialidade. É por isso que é essencial pôr em prática um tipo de educação libertadora que possa ajudar a tornar possíveis essas transformações, tal como concebidas pela posição intercultural, se esta está entre as culturas em jogo. (PALERMO; QUINTERO, 2014, p. 44). ${ }^{19}$ (Tradução livre minha).

Logo, essas atuais "políticas" de arte e de educação apenas podem ser compreendidas como ((des)políticas) para a cultura brasileira que é uma cultura de diferenças. Portanto, adverti que as minhas discussões não quiseram tratar da falta ou mesmo do apoio que as políticas públicas devem, no sentido compreendido pela grande maioria das pessoas, dar às artes, à educação, às culturas, à saúde e como promoção de segurança públicas, por exemplo, como se fossem incentivos e obrigações pelos quais nós não pagamos caro. Não quis propor aqui a manutenção da ideia de política relacionada às artes, à educação ou mesmo às outras necessidades sociais que as políticas não veem. Por fim, quis, como sinalizei deste o título do artigo,

${ }^{18}$ Caso se interesse por mais informações à respeito, conferir a integra da matéria disponível em: https://www.bbc.com/portuguese/brasil-51155070. Acesso em: 28 jan. 2020.

19 "Compartiendo estas críticas, dudo de que por sí sola la educación pueda resolver la desigualdad. Menos aún cuando estas políticas no está acompañadas por transformaciones profundas de los saberes, metodologías y finalidades. Así por ejemplo, aumentar la matrícula escolar por sí mismo, como un dado estadístico que mide el nivel de alfabetización [...], [militarizar, tecnicizar o impor políticas capitalistas no implica que se estén generando cambios en el funcionamento social que den como resultado una mayor simetría; otro tanto ocurre con la alfabetización de las comunidades originarias argentinas en sus lenguas, [...], no contribuirá a la descolonización y a la interculturalidad. Sin duda es necesario cambiar los contenidos, los lenguajes, los términos de la conversación, pero también transformar la disposición del poder, esto es de la colonialidade. Por eso es imprescindible la puesta en práctica de un tipo de educación libertadora que sí puede contribuir a posibilitar estas transformaciones tal como la concibe el posicionamiento intercultura si éste está entrando en las culturas en juego." (PALERMO; QUINTERO, 2014, p. 44-45).

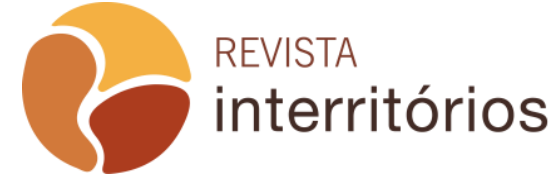

Interritórios | Revista de Educação Universidade Federal de Pernambuco, Caruaru, BRASIL | V.6 N.10 [2020] 
tratar das políticas do "Bozo" que estão em construção pela política partidária dirigente atual do país - atual já que confio na ideia de que todas elas serão depostas em bem breve tempo - que reforçam um conservadorismo que é fascista, extremista e direitista e que são, na grande verdade, (des)políticas para os corpos da arte, educação, das culturas das diferenças, da produção de conhecimentos por meio dos saberes, corpos que demandam saúde e segurança públicas que essas políticas atuais não contemplam como estão sendo muito mal pensadas. Aliás, a pobreza não é a maior inimiga do meio ambiente e pobres não "destroem porque estão com fome" como salientou o ministro da Economia, Paulo Guedes, em Davos, Suíça, no Fórum Econômico Mundial em janeiro deste ano. ${ }^{20}$ Estou, cada vez mais, acreditando na deposição desse cidadão do seu cargo de suposto dirigente maior do país por vias das suas próprias merda feitas e ditas todos os dias. Assim, não há políticas públicas de arte, de educação, saúde ou de segurança sendo pensadas que não sejam ideologicamente políticas partidárias priorizando os discursos de manutenção de exclusão das diferenças mais tradicionais edificados junto ao pensamento moderno. Do mesmo jeito, é impossível si ver diferente em um contexto como o atual da política brasileira em que estão priorizando literalmente o seu semelhante (EU) político (OS FILHOS). Do contrário, continuaremos tendo na arte e na educação a forma de governança das diferenças como se todas essas fossem iguais que na verdade desgoverna para o povo.

[...] a educação é a estratégia da colonialidade por excelência, de tal forma que é com ela que continua a consolidar - e às vezes com as melhores intenções, como campanhas intensivas de alfabetização [Enem, FURUTA-SE, Olimpíada disso ou daquilo, entre outras] - o funcionamento da matriz colonial na formação do imaginário, entendendo por estas as formas de perceber e compreender o mundo próprio de cada cultura, sempre conflituoso e contraditório. A força de imposição ao longo do tempo e múltiplas estratégias (desde a imposição da letra até a dos sistemas cibernéticos) torna tão difícil fazer mudanças profundas: modelos pedagógicos, práticas institucionais, conteúdos e formas e como eles são transmitidos e como constituem uma rede de relações muito consolidadas. (PALERMO, 2014, p. 45). ${ }^{21}$ (Tradução livre minha).

${ }^{20}$ Ver a integra da matéria em:

https://economia.uol.com.br/noticias/redacao/2020/01/21/pobres-destruicao-ambiental-pauloguedes.htm. Acesso em: 28 jan. 2020.

21 "[...] la educación es la estrategia de colonialidad por antonomasia, de modo tal que es con ella que se siguen consolidando -y a veces con las mejores intenciones como son las campañas intensivas de alfabetización- el funcionamiento de la matriz colonial en la formación de los imaginarios, entendiendo por éstos las formas de percibir y comprender el mundo propias de cada cultura, siempre conflictivas y contradictorias. La fuerza de imposición a través del tiempo y de múltiples estrategias (que van desde la imposición de la

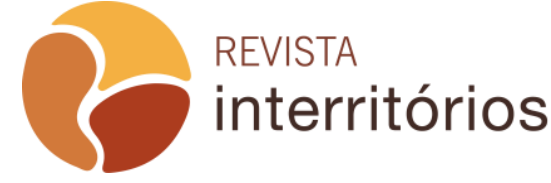

Interritórios | Revista de Educação Universidade Federal de Pernambuco, Caruaru, BRASIL | V.6 N.10 [2020] 
Para concluir tenho que dizer, não estive, em momento algum nessas reflexões reforçando esta ou aquela política partidária, como fiz questão de afirmar que não me coloquei em defesa também desta ou daquela arte e educação que não são reparadoras dos danos causados àqueles que precisam ser reparados dos danos históricos e contemporâneos e que são diferentes dos que precisam ser pa-ra-dos de fazer o que não deve. Do mesmo modo não quis defender a estandardização de uma ou de outra cultura diferentes. Falo o tempo todo aqui de DIREITOS PARA TOD@S que estão sendo retirados! Pois compreendo, uma coisa ou outra, na sua devida diferença colonial/imperial versus subalternização. Do mesmo modo, sei e acredito no funcionamento da matriz colonial na formação do imaginário, compreendendo ainda que é por meios de determinadas padronizações de arte, de cultura e de produção de conhecimentos que as formas estabelecidas definem como perceber e compreender o mundo próprio de cada cultura, especialmente as das diferenças colonizadas. À

Minha família Bessa, bom dia!

Esta noite me peguei pensando mais uma vez na atual situação brasileira na qual estamos totalmente inseridos. Às vésperas das eleições para elegermos governadores, em alguns lugares, e o presidente da república brasileira.

Não vou falar em defesa ou ataque a um ou outro candidato. Já temos muito ódio à solta. Mas gostaria que refletissem e se conscientizassem de algumas coisas:

Se você não tiver irmão, primo, sobrinho ou filho homossexual, lembre-se que temos vários desses que ainda estão em estado de formação humana e podem não se formar com direitos;

Se você nunca teve um irmão, primo, sobrinho ou filho que se envolveu com drogas, lembre-se que ninguém está livre disso em qualquer situação;

Se você nunca teve um problema de traição conjugal na sua família, lembre-se que a vida é sempre um futuro. O ser humano é um sujeito fraco e vive das circunstâncias;

Se você acha que o único modelo de família está ancorado na união de um homem com uma mulher, lembre-se daqueles ou daquelas que criam os seus parentes sozinhos com todo amor e carinho;

Se a escola dos seus filhos, sobrinhos, irmãos, primos não é a melhor opção hoje, sem ela não será possível garantir nada que temos ainda hoje;

letra hasta la de los sistemas cibernéticos) hace tan difícil la concreción de cambios profundos: los modelos pedagogícos, las prácticas institucionales, los contenidos y las formas como se transmiten constituyen una red de relaciones muy consolidada" (PALERMO, 2014, p. 45). 
Se você não for pobre, seja rico também de espírito, de amor, de fé, força e esperança e com Deus no coração. Mas sem dizer que o do outro não o é.

Não ao ódio, ao desprezo, ao racismo, ao pré-conceito.

Se você não tiver ninguém que dependa de emprego, de aposentadoria, saúde pública, educação pública e segurança pública, de alguém que precisa do direito de ir e vir, você conquistou isso, lembre-se que pode perder tudo quem já conquistou e não ter direito quem pensa em conquistar. É um direito do brasileiro.

Nós não precisamos de mais obrigações. Precisamos aumentar os nossos direitos. Mas também dar direito ao outro de conquistar.

Seriam tantas coisas que eu poderia dizer para vocês, mas APENAS PEÇO QUE PENSEM EM MIM. Eu, família de vocês, Marcos - professor concursado e que estudou com Bolsa Pública toda a formação para ser professor, homem e integro como sou por herança dessa família - mas que sou tudo isso que está em jogo e que pode vir a ser PERSEGUIDO PELA POLÍTICA DE ÓDIO daqui para frente se nós não elegermos um governador e/ou um presidente que respeite 0 direito do OUTRO ser DIFERENTE.

Beijos em todos!22

\section{REFERÊNCIAS}

BARROS, Manoel de. Arranjos para assobio. 2. ed. Rio de Janeiro: Record, 1998. BASE NACIONAL COMUM CURRICULAR. In: MEC. Base Nacional Comum Curricular. Disponível em: http://basenacionalcomum.mec.gov.br/. Acesso em: 27 ago. 2017.

BESSA-OLIVEIRA, Marcos Antônio. As fronteiras que es $\square \mathrm{m}$ as produções culturais da exterioridade. In: ANAIS - 13 CICLO DE INVESTIGAÇÕES EM

ARTES VISUAIS - PPGAV/CEART/UDESC, 2018, p. 74-83. Disponível em: https://www.udesc.br/arquivos/ceart/id cpmenu/7750/ANAIS ciclo ppgav udesc 20 18 FINAL 1562789061679 7750.pdf. Acesso em: 29 jul. 2019.

BESSA-OLIVEIRA, Marcos Antônio. Biogeografias artísticas como exterioridade dos fazeres - corpos latinos fronteiriços. In: Cadernos de Estudos Culturais:

Exterioridade dos Saberes: NECC 10 ANOS, v. 2, n. 20, 2018a. Disponível em: https://periodicos.ufms.br/index.php/cadec/article/view/7772. Acesso em: 02 jul. 2019.

BESSA-OLIVEIRA, Marcos Antônio. Ensino de Artes X Estudos Culturais: para além dos muros da escola. São Carlos, SP: Pedro \& João Editores, 2010.

BRASIL. Constituição Federal de 1988. Promulgada em 5 de outubro de 1988.

22 Texto compartilhando no grupo da família Bessa no dia 26 de outubro de 2018 às 11 h54min, vésperas do $2^{\circ}$ turno das eleições de 2018 para Presidente da República que ocorreu no dia 28 de outubro daquele ano, do qual participava até o dia do resultado daquelas eleições.

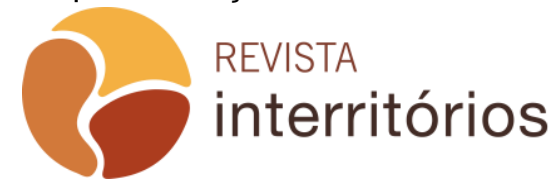

Interritórios | Revista de Educação Universidade Federal de Pernambuco, Caruaru, BRASIL | V.6 N.10 [2020] 
Disponível em: http://www.planalto.gov.br/ccivil 03/constituicao/constituição.htm. Acesso em: 09 set. 2019.

BRASIL. Ministério de Educação e Cultura. LDB - Lei no 9394/96, de 20 de dezembro de 1996. Estabelece as diretrizes e bases da Educação Nacional. Brasília: MEC, 1996. Disponível em:

http://www.planalto.gov.br/ccivil 03/leis/L9394.htm. Acesso em: 09 ago. 2019.

DERRIDA, Jacques. Políticas da amizade. Tradução Fernanda Bernardo. Porto: Campo das Letras - Editores S.A., 2003.

FARIA, J. R.; BESSA-OLIVEIRA, M. A. Meu/nosso corpo estranho, o que temos é dele/nele que somos. Filosofia e Educação, v. 11, n. 1, p. 5-35, 9 set. 2019. Disponível em:

https://periodicos.sbu.unicamp.br/ojs/index.php/rfe/article/view/8655077. Acesso em: 28 out. 2019.

MIGNOLO, Walter D.. "Prefacio". In: PALERMO, Zulma. Para una pedagogia decolonial. 1 ed. Ciudad Autónoma de Buenos Aires: Del Signo, 2014a. (El desprendimento / Walter Mignolo), p. 7-9.

MIGNOLO, Walter D.. Desobediência epistêmica: a opção descolonial e o significado de identidade em política. In: Cadernos de Letras da UFF: Dossiê: Literatura, língua e identidade, n.34, 2008, p. 287-324. Disponível em: www.uff.br/ cadernosdeletrasuff/34/traducao.pdf. Acesso em: 08 jul. 2018.

MIGNOLO, Walter D.. La idea de América Latina: La herida colonial y la opción decolonial. Traducción de Silvia Jawerbaum y Julieta Barba. Primera edición: mayo de 2007, Barcelona- Espanâ: Editorial Gedisa, S.A, 2007.

MIGNOLO, Walter. Desafios decoloniais hoje. Trad. de Marcos de Jesus Oliveira. Epistemologias do Sul: Pensamento Social e Político em/desde/para América Latina, Caribe, África e Ásia, v.1, n. 1, Foz do Iguaçu/PR: Universidade Federal da Integração Latino-Americana, p. 12-32. 2017. Disponível em: https://revistas.unila.edu.br/epistemologiasdosul/article/view/772/645. Acesso em: 27 mar. 2018.

ORTEGA, Francisco. Para uma política da amizade. Arendt, Derrida, Foucault. Rio de Janeiro: Relume Dumará, 2000.

PALERMO, Zulma. Para una pedagogia decolonial. 1 ed. Ciudad Autónoma de Buenos Aires: Del Signo, 2014. (El desprendimento / Walter Mignolo).

PALERMO, Zulma; QUINTERO, Pablo. “La matriz colonial de poder en diálogo". In: PALERMO, Zulma. Para una pedagogia decolonial. 1 ed. Ciudad Autónoma de Buenos Aires: Del Signo, 2014a. (El desprendimento / Walter Mignolo), p. 21-57.

QUIJANO, Aníbal. “Colonialidad y modemidad/racionalidad”. In: Perú Indígena, 13, 29, 1992, p. 1-20. Disponível em: https://www.lavaca.org/wpcontent/uploads/2016/04/quijano.pdf. Acesso em: 08 de jul. 2018. 